\title{
Cerebral Responses to Single and Multiple Cocaine Injections in Newborn Sheep
}

\author{
THOMAS P. O'BRIEN, CHRISTINE A. GLEASON, M. DOUGLAS JONES, Jr., EDWARD J. CONE, \\ EDYTHE D. LONDON, AND RICHARD J. TRAYSTMAN

\begin{abstract}
Eudowood Neonatal Pulmonary Division, Departments of Pediatrics, Anesthesiology/Critical Care Medicine, and Ginecology and Obstetrics, The Johns Hopkins University' School of Medicine, Baltimore, Maryland 21287-3200 [T.P.O., C.A.G., M.D.J., R.J.T.J; Addiction Research Conter, National Institute on Drug Abuse, Baltimore, Maryland 21224 [E.J.C., E.D.L.]; and Department of Pharmacology and Experimental Therapeutics, University of Maryland School of Medicine, Baltimore, Maryland 21201 [E.D.L.]
\end{abstract}

\begin{abstract}
Newborn infants exposed to cocaine near birth display a wide range of neurologic abnormalities, but the mechanism or mechanisms for these injuries remain unknown. We studied the cerebral effects of a single acute dose $(4 \mathrm{mg} / \mathrm{kg} ; n=7)$ and multiple binge doses $(4 \mathrm{mg} / \mathrm{kg}$ hourly for $5 \mathrm{~h} ; n=7$ ) of i.v. cocaine in unanesthetized newborn $(5 \pm 1 \mathrm{~d}$ old $)$ sheep. We measured cerebral blood flow, mean arterial blood pressure, arterial blood gases, and cerebral $\mathrm{O}_{2}$ metabolism. Measurements were made at baseline; $30 \mathrm{~s}$; and 5,15 , and $60 \mathrm{~min}$ after a single injection of cocaine in the acute group and at the same time intervals after the 5th dose of cocaine in the binge group. CBF increased by $98 \pm 68 \%$ (mean $\pm \mathrm{SD}$ ) at $30 \mathrm{~s}$ after a single acute dose and by $97 \pm 94 \%$ at $30 \mathrm{~s}$ after the 5 th of five hourly binge doses. Although it returned to baseline by 5 min in the acute group, cerebral blood flow remained elevated 5,15 , and $60 \mathrm{~min}$ after the 5 th cocaine dose in the binge group. At $30 \mathrm{~s}$, mean arterial blood pressure increased by $57 \pm 21 \%$ in the acute group and $46 \pm 15 \%$ in the binge group. In both groups, mean arterial blood pressure remained elevated at $5 \mathrm{~min}$. Although no change occurred in cerebral $\mathrm{O}_{2}$ metabolism in the acute group, an increase in cerebral $\mathrm{O}_{2}$ consumption $(7.4 \pm 1.3 \mathrm{~mL} / 100 \mathrm{~g} /$ min versus $5.5 \pm 1.1$ at baseline) was observed at $5 \mathrm{~min}$ in the binge group. Thus, injection of cocaine as a single acute dose or after multiple binge doses results in acute cerebral vasodilation and hypertension in newborn sheep. Acute cerebral vasodilation, when combined within hypertension, may partially explain the pathogenesis of cocaine-associated neonatal neurologic abnormalities. (Pediatr Res 35: $339-343,1994)$
\end{abstract}

Abbreviations

CBF, cerebral blood flow

$\mathrm{CMRO}_{2}$, cerebral oxygen consumption

Neurologic complications after prenatal and postnatal cocaine exposure have been well described $(1,2)$. In newborns, these complications range from increased muscle tone and irritability to seizures and cerebral infarction. Although the properties of cocaine as a potent vasoconstrictor of peripheral vessels are well known (3), conflicting reports exist concerning the effects of

Received June 3, 1993; accepted October 7, 1993.

Correspondence: Thomas P. O'Brien, M.D.. Division of Neonatology, The Johns Hopkins Hospital, CMSC 210, 600 N. Wolfe St., Baltimore, MD 21287-3200.

Supported by NIDA 06658 and by Eudowood, formerly the Hospital for the Consumptives of Maryland. cocaine on the cerebral circulation. There are reports demonstrating cerebral vasoconstriction $(4,5)$ and vasodilation $(6)$. Furthermore, little systematic data exist concerning effects of cocaine on CBF and metabolism in the newborn. In addition, cocaine is frequently consumed in binges in which the drug is used repeatedly until both the addict and supply are exhausted. Fischman et al. (7) reported the development of acute tolerance both to the cardiovascular and subjective effects of cocaine in human addict volunteers. We tested the hypothesis that newborn cerebral responses to repeated binge doses of cocaine differ from responses to a single acute dose.

\section{MATERIALS AND METHODS}

Subjects. Fourteen newborn sheep (mean age, $5 \pm 1 \mathrm{~d}, 9$ male) were used for the study; seven (mean weight, $4.5 \pm 0.6 \mathrm{~kg}$ ) received a single $4 \mathrm{mg} / \mathrm{kg}$ i.v. dose of cocaine hydrochloride, and seven (mean weight, $5.0 \pm 1.4 \mathrm{~kg}$ ) received five hourly $4 \mathrm{mg} / \mathrm{kg}$ doses. Three additional animals (mean age, $4 \pm 1 \mathrm{~d}$; mean weight. $4.6 \pm 0.9 \mathrm{~kg}$ ) were studied for $5 \mathrm{~h}$ to demonstrate the stability of this unanesthetized animal preparation. All surgical and experimental procedures were approved by our Institutional Animal Care and Use Committee.

Surgical preparation. Newborn sheep were brought to the animal care facility with their ewes on the day before study. The animals were given 450000 units of procaine penicillin intramuscularly before surgery. All cutaneous sites of entry were prepared with alcohol and betadine solution. The sheep were anesthetized with pentobarbital ( 15 to $20 \mathrm{mg} / \mathrm{kg}$ ) via a catheter placed percutaneously in the external jugular vein. Additional doses of pentobarbital (1 to $2 \mathrm{mg} / \mathrm{kg}$ ) were administered as needed.

Polyvinyl chloride catheters were then placed into the left ventricle and brachiocephalic artery (via the axillary arteries) and into both femoral arteries and a femoral vein. The catheters were flushed and filled with heparinized saline $(10 \mathrm{IU} / \mathrm{mL})$, sutured to the skin, and placed in a pouch attached to the abdomen.

The sagittal, coronal, and lambdoid sutures were identified, and a shallow burr hole was drilled over the sagittal suture approximately $0.5 \mathrm{~cm}$ anterior to the lambda. The sagittal sinus was identified and the overlying dura punctured with a no. 19 gauge needle. A polyvinyl chloride catheter was then inserted into the sagittal sinus, and its tip was positioned anterior to the confluence of the sinuses to minimize contamination from extracerebral venous blood. The catheter was then flushed and filled with heparinized saline and sutured securely to the scalp. The sheep were then weighed and allowed to recover in the laboratory until they could stand and suckle; they were then returned to their mothers. The next day the sheep were brought back to the laboratory. Recovery from anesthesia and surgery 
was assessed by clinical examination, suckling behavior, and measurement of baseline arterial blood gas and $\mathrm{pH}$ values, glucose and lactate concentrations, and hematocrit value. These physiologic parameters were consistent with previous studies from our laboratory in anesthetized or sedated newborn sheep who had undergone surgery $1 \mathrm{~d}$ previously.

Physiologic measurements. Blood flow was measured by the radiolabeled microsphere technique (8). Approximately $1 \times 10^{6}$ microspheres $(0.4 \mathrm{~mL})$, labeled with ${ }^{153} \mathrm{Gd},{ }^{114} \mathrm{In},{ }^{113} \mathrm{Sn},{ }^{103} \mathrm{Ru}$, ${ }^{95} \mathrm{Nb}$, or ${ }^{46} \mathrm{Sc}$ (DuPont-New England Nuclear, Boston, MA), were injected into the left ventricle for a $0.5-\mathrm{min}$ period. A reference blood sample was withdrawn from the brachiocephalic artery at a rate of $2.53 \mathrm{~mL} / \mathrm{min}$ beginning $1 \mathrm{~min}$ before injection and continuing for $1.5 \mathrm{~min}$ after the injection was completed. The injections of microspheres were not associated with changes in heart rate or blood pressure.

At autopsy, the brain was removed at the base and divided at the cephalic border of the pons. Blood flow was measured separately for cerebrum, cerebellum, and brain stem (pons and medulla). Radioactivity in tissue samples was determined with a model 5530 gamma counter (Packard, Downers Grove, IL). All reference blood and tissue samples contained more than 400 microspheres.

Blood samples for $\mathrm{pH}$, arterial $\mathrm{CO}_{2}$ partial pressure, arterial $\mathrm{O}_{2}$ partial pressure, $\mathrm{O}_{2}$ saturation, hemoglobin concentration, and hematocrit were withdrawn into heparinized syringes. Respiratory blood gas values and $\mathrm{pH}$ were measured at $39.5^{\circ} \mathrm{C}$ with a model ABL 30 blood gas analyzer (Radiometer America, Westlake, $\mathrm{OH}$ ). Oxygen saturation and hemoglobin concentration were measured with a model OSM-3 Hemoximeter (Radiometer America). Arterial hematocrit was measured by the microhematocrit technique. Arterial blood pressure and heart rate were continuously monitored (model 2400, Gould Instruments, Oxnard, CA) throughout the experiment.

Levels of cocaine and its metabolites were measured in arterial blood collected in tubes containing $0.1 \mathrm{~mL}$ of enzyme inhibitor (equal parts of a saturated sodium fluoride solution and a $10 \%$ solution of glacial acetic acid) per $2.0 \mathrm{~mL}$ of blood. The blood was mixed with the inhibitor and centrifuged, and the plasma were stored frozen $\left(-70^{\circ} \mathrm{C}\right)$ until analyzed. Analysis for cocaine and its metabolites was performed by electron impact gas chromatography-mass spectrometry (multiple ion monitoring) after extraction with solid-phase extraction cartridges as described by Cone et al. (9). Deuterated internal standards were used for quantitation. The assay gave a linear response across a concentration range of $5-250 \mu \mathrm{g} / \mathrm{L}$ and had a limit of detection of 1.0 $\mu \mathrm{g} / \mathrm{L}$. The limit of quantitation by this assay was $5.0 \mu \mathrm{g} / \mathrm{L}$ for each analyte.

Plasma epinephrine and norepinephrine concentrations were measured by HPLC with electrochemical detection as described by Nishijima et al. (10). Whole blood $(5 \mathrm{~mL})$ was collected in a tube containing $50 \mu \mathrm{L}$ EDTA, and the plasma was frozen at $-70^{\circ} \mathrm{C}$ until analyzed. Samples were purified by alumina absorption. Epinephrine and norepinephrine were oxidized at $650 \mathrm{mV}$ (versus $\mathrm{Ag} / \mathrm{AgCl}$ ) on a bioanalytical systems' vitreous carbon working electrode. An integrator quantified catechols by internal standardization. The sensitivity of the assay was $20 \mathrm{ng} / \mathrm{L}$.

Experimental protocol. On the day of the study $(24 \mathrm{~h}$ after surgery), the animals were brought to the laboratory and placed in wooden crates. Six measurements were made during the study. For each measurement, blood samples were drawn first, and then microspheres were injected into the left ventricle while a reference sample was withdrawn from the brachiocephalic artery. Two baseline measurements were obtained.

Three groups of animals were studied: acute $(n=7)$, binge $(n=7)$, and time-controls $(n=3)$. In the acute group, blood flow was measured at $30 \mathrm{~s}$ and at 5,15 , and $60 \mathrm{~min}$ after i.v. injection of $4 \mathrm{mg} / \mathrm{kg}$ of cocaine hydrochloride (Sigma Chemical, St. Louis, MO). In the binge group, $4 \mathrm{mg} / \mathrm{kg}$ of cocaine hydrochloride was injected at hourly intervals for $5 \mathrm{~h}$. Blood flow measurements were made at $30 \mathrm{~s}$ and at 5,15 , and $60 \mathrm{~min}$ after the 5 th dose. We chose a dose of $4 \mathrm{mg} / \mathrm{kg}$ for several reasons. First, pilot data showed that newborn cocaine levels at $5 \mathrm{~min}$ after a $4 \mathrm{mg} / \mathrm{kg}$ dose were similar to cocaine levels obtained in our laboratory in maternal and fetal sheep 5 min after a $2 \mathrm{mg} /$ $\mathrm{kg}$ dose (11). Second, the newborn cocaine levels at $5 \mathrm{~min}$ were $60 \%$ higher than human cocaine levels reported 30 min after a moderate $(40 \mathrm{mg})$ cocaine dose $(20)$. Third, pilot studies did not reveal any untoward side effects (seizures, fatal arrhythmias) with this dose. In the time-control group, six measurements were made hourly over a 5-h period; no injections were given.

Samples for determination of cocaine and catecholamine levels were drawn before administration of cocaine and at 5 and 15 min after injection. In the binge group, these levels were obtained at 5 and $15 \mathrm{~min}$ after the 5 th dose of cocaine.

At the end of the study, the sheep were anesthetized with pentobarbital and killed with an overdose of saturated $\mathrm{KCl}$ solution. Catheter positions were verified. The brain was removed, weighed, and dissected for analysis of regional blood flow.

Data analysis and calculations. Organ blood flow was calculated as follows: cpm organ/cpm ref $\times$ reference withdrawal rate $(\mathrm{mL} / \mathrm{min})$, where $\mathrm{cpm}$ organ and $\mathrm{cpm}$ ref represent radioactive $\mathrm{cpm}$ in the organ and reference samples, respectively. $\mathrm{CMRO}_{2}$ was calculated as follows: $\left(\mathrm{CaO}_{2}-\mathrm{CvO}_{2}\right) \times \mathrm{CBF}$, where $\mathrm{CaO}_{2}$ and $\mathrm{CvO}_{2}$ represent arterial and venous oxygen content, respectively. Cerebral oxygen transport was calculated as $\mathrm{CaO}_{2} \times \mathrm{CBF}$. Cerebral fractional oxygen extraction was calculated as follows: $\mathrm{CMRO}_{2} \div \mathrm{O}_{2}$ transport. Vascular resistance was calculated as MAP $\div$ blood flow, where MAP is mean arterial pressure.

Differences within groups were tested by one-way analysis of variance for repeated measures. If the $F$ test indicated significance, differences between individual means were tested with the Newman-Keuls test. Logarithmic transformations were used when the SD increased with the mean value. An unpaired $t$ test was used to identify differences between groups. Significance was set at $p<0.05$. All results are expressed as mean \pm SD.

\section{RESULTS}

Regional brain blood flows and vascular resistance are shown in Figures 1 and 2 . In the acute group, a single $4 \mathrm{mg} / \mathrm{kg}$ i.v. injection of cocaine resulted in a $98 \pm 68 \%$ increase in CBF at $30 \mathrm{~s}$. Five minutes after injection, $\mathrm{CBF}$ returned to baseline. Coinciding with the increase in CBF at $30 \mathrm{~s}$ was a decrease in cerebral vascular resistance. In the binge group, five hourly 4 $\mathrm{mg} / \mathrm{kg}$ injections of cocaine resulted in a $97 \pm 94 \%$ increase in CBF $30 \mathrm{~s}$ after the final dose. This increase was sustained 5,15 , and $60 \mathrm{~min}$ after injection. Changes in brain stem and cerebellar flow paralleled changes in CBF, with the greatest increase seen in cerebellum at $30 \mathrm{~s}$. In the binge group, cerebral vascular resistance decreased at 15 and $60 \mathrm{~min}$ after injection. In comparing acute and binge groups, flow measurements at baseline, $30 \mathrm{~s}$, and $5 \mathrm{~min}$ were not different. In the binge group, however, brain blood flow compared with baseline remained greater in brain stem and cerebellum at 15 and $60 \mathrm{~min}$.

Data on $\mathrm{CMRO}_{2}$ are shown in Table $1 . \mathrm{CMRO}_{2}$ was not altered after a single acute dose. In the binge group, however, $\mathrm{CMRO}_{2}$ and oxygen transport increased compared with baseline at $5 \mathrm{~min}$. In both groups, fractional oxygen extraction was unchanged.

Cardiovascular variables, arterial blood gases, and hematocrit values are shown in Table 2 . In both groups, mean arterial pressure increased at $30 \mathrm{~s}$. This increase was sustained at $5 \mathrm{~min}$ and returned to baseline by $15 \mathrm{~min}$. Heart rate was unchanged ( $p=0.08,30 \mathrm{~s}$ versus baseline) in both groups. Although arterial $\mathrm{pH}$ in the acute group decreased, no change occurred in arterial blood gas measurements in the binge group. Hematocrit was unchanged in both groups.

Plasma norepinephrine and epinephrine levels are shown in 

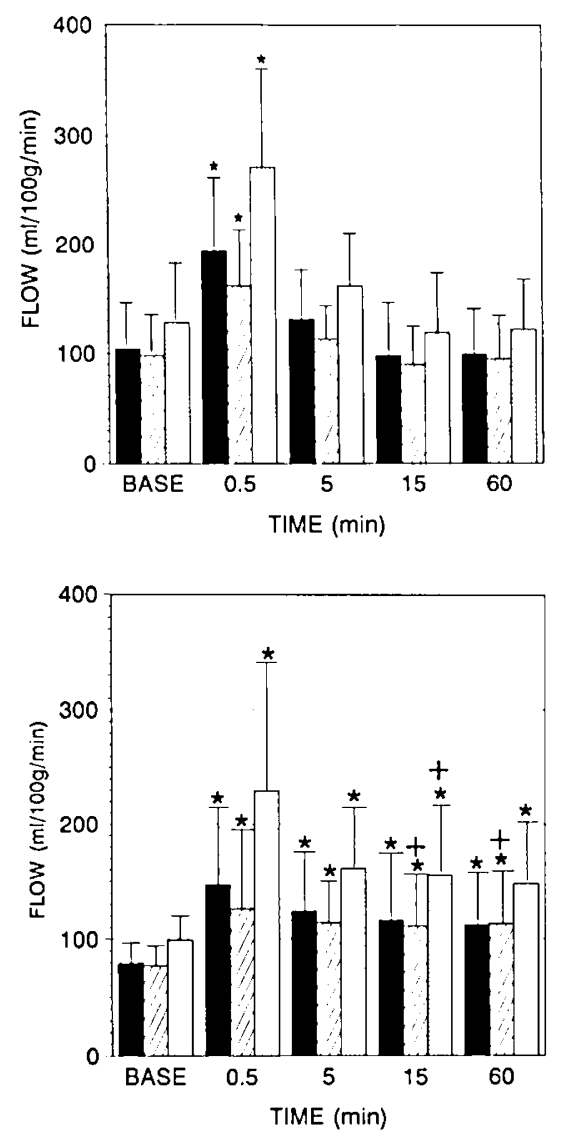

BINGE

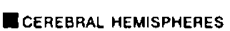

DBainstem

$\square$ CEREBELLUM

Fig. 1. Regional brain blood flows after single (acute) and multiple (binge) doses of cocaine ( $4 \mathrm{mg} / \mathrm{kg}$ each dose). Values expressed as mean $\pm \mathrm{SD} ; n=$ seven acute, $n=$ seven binge. ${ }^{*}, P<0.05$ compared with baseline. $\dagger, p<0.05$ acute compared with binge.

Table 3. In the acute group, an increase occurred in both norepinephrine and epinephrine at $5 \mathrm{~min}$ after injection. In the binge group, an increase in norepinephrine occurred at 5 and 15 min after the final injection, whereas epinephrine levels were only elevated at $5 \mathrm{~min}$. When the two groups were compared, the binge group had higher catecholamine levels than the acute group at $15 \mathrm{~min}$.

Plasma cocaine, benzoylecgonine, and ecgonine methyl ester levels are shown in Table 4. Although cocaine levels rose at 5 min after injection in both groups, metabolism was rapid, and cocaine levels were not significantly different from baseline by $15 \mathrm{~min}$. Cocaine was rapidly metabolized to ecgonine methyl ester in both groups. Levels of both metabolites in the binge group were higher than the acute group at 5 and $15 \mathrm{~min}$.

Over a 5-h study period, the three time-control animals showed no changes in CBF, cerebral oxidative metabolism, heart rate, blood pressure, arterial blood gases, or hematocrit.

\section{DISCUSSION}

The most important findings of this study are as follows: 1 ) i.v. cocaine given in a single acute dose or multiple binge doses increased $\mathrm{CBF}$ at $30 \mathrm{~s}$; in the binge group this increase was sustained for $60 \mathrm{~min} ; 2$ ) in the binge group, the increase in CBF was accompanied by an increase in $\mathrm{CMRO}_{2}$ at $5 \mathrm{~min}$; and 3) the binge group showed no development of acute tolerance to the systemic vasopressor effects of cocaine.

Although cocaine's ability to constrict peripheral blood vessels is well known (3), little systematic data exist concerning cocaine's effect on the cerebrovascular system. Dohi et al. (6) found that cocaine produced vasodilation when applied directly to cat cerebral arterioles. This vasodilator response was blocked by i.v.

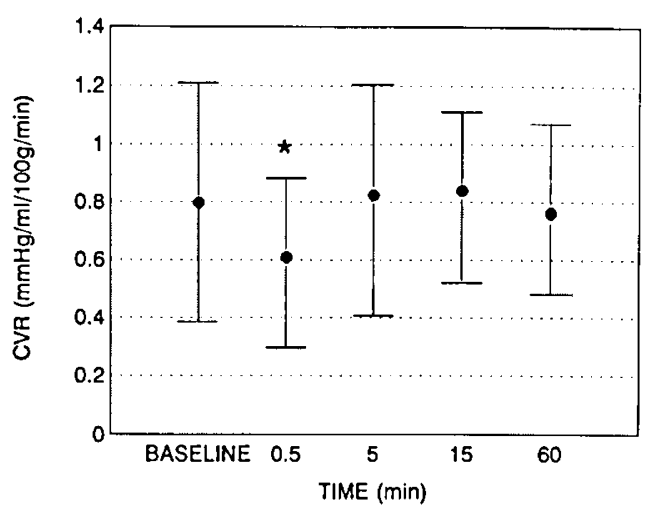

ACUTE

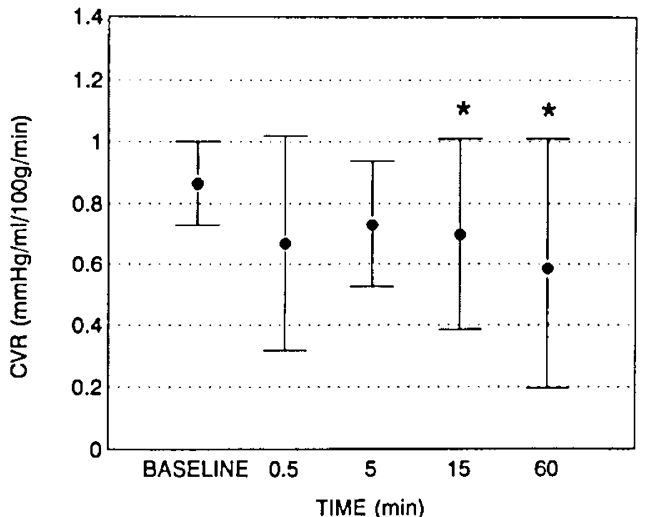

BINGE

Fig. 2. Cerebrovascular resistance $(C V R)$ after single (acute) and multiple (binge) doses of cocaine ( $4 \mathrm{mg} / \mathrm{kg}$ each dose). Values expressed as mean $\pm \mathrm{SD} ; n=$ seven acute, $n=$ seven binge. ${ }^{*}, p<0.05$ compared with baseline.

propranolol. Sharkey et al. (12) found that i.v. cocaine increased local CBF associated with an increase in local cerebral glucose use in certain regions of rat brain. They concluded that it was unlikely that vasospasm was the primary mechanism underlying cocaine-induced cerebrovascular accidents. In human infants, Van de Bor et al. (13) demonstrated an increase in CBF velocity measured by pulsed Doppler cranial ultrasonography in infants born to mothers who abused cocaine. Other authors have reported cocaine-induced cerebral vasoconstriction. Albuquerque et al. $(4,14)$ demonstrated vasoconstriction in piglet pial arterioles exposed to cocaine and its metabolites. Madden and Powers (5) described spasm of isolated cat cerebral arteries exposed to cocaine and its major metabolites. In another in vitro model, Schreiber $e t$ al. (15) found vasoconstriction of isolated lamb cerebral arteries when they were exposed to cocaine and its metabolite benzoylecgonine. Some of these conflicting data may reflect species differences, differences in method, anesthesia technique, or some combination of these three.

In this study, cocaine may have increased $C B F$ with vasodilation by one of three mechanisms. The first potential mechanism is a substantive increase in blood pressure exceeding the limits of cerebral autoregulation. Arnold et al. (16) demonstrated that global brain blood flow was independent of mean arterial blood pressure over the range of 45 to $82 \mathrm{~mm} \mathrm{Hg}$ in newborn lambs. The degree of hypertension observed in our experiments after a single acute dose of cocaine (67 to $104 \mathrm{~mm} \mathrm{Hg}$ ) is above these limits of autoregulation. Therefore, the hypertension may have resulted in an increase in CBF. However, we still found a significant and sustained increase in CBF in the binge group when blood pressure remained well within the limits of autoregulation. Thus, we believe hypertension alone cannot explain the increase in CBF. However, if forced vasodilation of cerebral vessels caused by acute hypertension resulted in vascular endothelial damage, normal autoregulatory responsivity of the vessels 
Table 1. Comparison of $\mathrm{CMRO}_{2}$, oxygen transport, and fractional oxygen extraction after single (acute) and multiple (binge) doses of cocaine*

\begin{tabular}{|c|c|c|c|c|}
\hline & \multirow[b]{2}{*}{ Baseline } & \multicolumn{3}{|c|}{ Time after cocaine injection (min) } \\
\hline & & 5 & 15 & 60 \\
\hline \multicolumn{5}{|l|}{ Acute } \\
\hline $\mathrm{CMRO}_{2}(\mathrm{~mL} / 100 \mathrm{gm} / \mathrm{min})$ & $5.8 \pm 1.3$ & $6.4 \pm 1.2$ & $5.6 \pm 2.2$ & $6.1 \pm 1.7$ \\
\hline Oxygen transport $(\mathrm{mL} / 100 \mathrm{gm} / \mathrm{min})$ & $12.5 \pm 3.2$ & $15.3 \pm 3.4$ & $12.2 \pm 5.2$ & $12.1 \pm 3.8$ \\
\hline Fractional oxygen extraction & $0.47 \pm 0.08$ & $0.42 \pm 0.05$ & $0.46 \pm 0.1$ & $0.51 \pm 0.1$ \\
\hline \multicolumn{5}{|l|}{ Binge } \\
\hline $\mathrm{CMRO}_{2}(\mathrm{~mL} / 100 \mathrm{gm} / \mathrm{min})$ & $5.5 \pm 1.1$ & $7.4 \pm 1.3 \dagger$ & $6.2 \pm 1.1$ & $6.2 \pm 1.0$ \\
\hline Oxygen transport $(\mathrm{mL} / 100 \mathrm{gm} / \mathrm{min})$ & $11.7 \pm 1.4$ & $17.2 \pm 3.5 \dagger$ & $16.1 \pm 3.4$ & $14.3 \pm 4.1$ \\
\hline Fractional oxygen extraction & $0.47 \pm 0.06$ & $0.43 \pm 0.07$ & $0.40 \pm 0.07$ & $0.45 \pm 0.05$ \\
\hline
\end{tabular}

* Values expressed as mean $\pm \mathrm{SD} ; n=$ seven acute, seven binge.

$\dagger p<0.05$ compared with baseline.

Table 2. Mean arterial blood pressure, heart rate, arterial blood gas values, and hematocrit after single (acute) and multiple (binge) doses of cocaine*

\begin{tabular}{|c|c|c|c|c|c|}
\hline & \multirow[b]{2}{*}{ Baseline } & \multicolumn{4}{|c|}{ Time after cocaine injection ( $\mathrm{min}$ ) } \\
\hline & & 0.5 & 5 & 15 & 60 \\
\hline \multicolumn{6}{|l|}{ Acute } \\
\hline $\mathrm{MAP}(\mathrm{mm} \mathrm{Hg})$ & $67 \pm 11$ & $104 \pm 12 \dagger$ & $88 \pm 11 \dagger$ & $72 \pm 6$ & $65 \pm 16$ \\
\hline Heart rate (beats/min) & $186 \pm 38$ & $228 \pm 24$ & $191 \pm 30$ & $182 \pm 18$ & $172 \pm 29$ \\
\hline $\mathrm{pH}$ & $7.43 \pm 0.03$ & & $7.37 \pm 0.05 \dagger$ & $7.38 \pm 0.06 \dagger$ & $7.38 \pm 0.06 \dagger$ \\
\hline $\mathrm{PaCO}_{2}(\mathrm{kPa})$ & $5 \pm 0.5$ & & $6 \pm 0.7$ & $5 \pm 0.8$ & $5 \pm 0.8$ \\
\hline $\mathrm{PaO}_{2}(\mathrm{kPa})$ & $13 \pm 1.7$ & & $13 \pm 1.6$ & $13 \pm 1.3$ & $13 \pm 0.8$ \\
\hline Hematocrit & $0.31 \pm 0.07$ & & & & $0.27 \pm 0.07$ \\
\hline \multicolumn{6}{|l|}{ Binge } \\
\hline $\mathrm{MAP}(\mathrm{mm} \mathrm{Hg})$ & $68 \pm 10$ & $92 \pm 8 \dagger$ & $88 \pm 14 \dagger$ & $71 \pm 10$ & $59 \pm 11$ \\
\hline Heart rate (beats/min) & $171 \pm 34$ & $212 \pm 26$ & $201 \pm 41$ & $209 \pm 42$ & $197 \pm 60$ \\
\hline $\mathrm{pH}$ & $7.41 \pm 0.03$ & & $7.38 \pm 0.05$ & $7.38 \pm 0.04$ & $7.40 \pm 0.03$ \\
\hline $\mathrm{PaCO}_{2}(\mathrm{kPa})$ & $6 \pm 0.8$ & & $5 \pm 0.9$ & $6 \pm 0.9$ & $5 \pm 1.2$ \\
\hline $\mathrm{PaO}_{2}(\mathrm{kPa})$ & $12 \pm 0.9$ & & $13 \pm 2$ & $12 \pm 2.5$ & $11 \pm 2.4$ \\
\hline Hematocrit & $0.33 \pm 0.07$ & & & & $0.29 \pm 0.05$ \\
\hline
\end{tabular}

*Values expressed as mean $\pm \mathrm{SD} ; n=$ seven acute, seven binge. MAP, mean arterial blood pressure; $\mathrm{PaCO}_{2}$, arterial $\mathrm{CO}_{2}$ partial pressure; PaO arterial $\mathrm{O}_{2}$ partial pressure.

$\dagger p<0.05$ compared with baseline.

Table 3. Epinephrine and norepinephrine levels $(n g / L)$ after single (acute) and multiple (binge) doses of cocaine*

\begin{tabular}{|c|c|c|c|}
\hline & \multirow[b]{2}{*}{ Baseline } & \multicolumn{2}{|c|}{$\begin{array}{l}\text { Time after cocaine injection } \\
\qquad(\mathrm{min})\end{array}$} \\
\hline & & 5 & 15 \\
\hline \multicolumn{4}{|l|}{ Acute } \\
\hline Epinephrine & $123 \pm 87$ & $301 \pm 107 \dagger$ & $138 \pm 129$ \\
\hline Norepinephrine & $554 \pm 722$ & $880 \pm 537 \dagger$ & $525 \pm 488$ \\
\hline \multicolumn{4}{|l|}{ Binge } \\
\hline Epinephrine & $172 \pm 136$ & $558 \pm 499 \dagger$ & $473 \pm 640 \ddagger$ \\
\hline Norepinephrine & $593 \pm 494$ & $1812 \pm 1160 \dagger$ & $1633 \pm 1131+\ddagger$ \\
\hline
\end{tabular}

may also have been affected. A second potential mechanism involves an increase in cerebral metabolism. CBF and cerebral metabolic requirements are usually closely coupled. (17) $\mathrm{CMRO}_{2}$ is 5 to $6 \mathrm{~mL} / 100 \mathrm{gm} / \mathrm{min}$ in unanesthetized newborn lambs, (18) and our baseline values were similar. We found an increase in $\mathrm{CMRO}_{2}$ and oxygen transport in the binge group at $5 \mathrm{~min}$. Although we did not measure glucose use, London et al. (19) demonstrated that cocaine stimulated regional cerebral metabolic rate for glucose in cocaine-naive rats. Similarly, Sharkey $e t$ al. (12) found an increase in cerebral glucose consumption and CBF after acute cocaine exposure in the rat. Their study demonstrated no evidence that cocaine exerted a direct action on the cerebral vascular bed without exerting changes in cerebral metabolic activity. Although London et al. (20) later demonstrated a cocaine-induced reduction in regional cerebral metabolic rate for glucose in the human brain, inconsistencies may have reflected differences in species, method, or prior drug history. It may be that changes in cerebral metabolism represent a dynamic process that depends on the chronicity of drug exposure. Our data do not concur with a previous report of cerebral vasoconstriction associated with a fall in $\mathrm{CMRO}_{2}$ in newborn piglets. (21) Several factors may account for this: 1 ) species differences (newborn lambs have more mature brains than piglets); 2) differences in anesthesia (the fall in $\mathrm{CMRO}_{2}$ was demonstrated in a group of animals anesthetized with morphine); or 3 ) differences in experimental protocols. The mechanism or mechanisms by which cocaine increases $\mathrm{CMRO}_{2}$ are not known but may relate to alterations in cerebral norepinephrine levels. Cocaine inhibits reuptake of norepinephrine, leading to increased levels at the synaptic cleft (22). In both groups, we found a marked increase in plasma norepinephrine levels after administration of cocaine. MacKenzie et al. (23) demonstrated that increases in central norepinephrine significantly increased $\mathrm{CMRO}_{2}$ and $\mathrm{CBF}$ in baboons. In our study, the increase in plasma norepinephrine levels was more marked and sustained in the binge group. Similarly, higher central norepinephrine levels might explain the differences we found in $\mathrm{CMRO}_{2}$ and $\mathrm{CBF}$ between the two groups. A final possible mechanism for the increase in CBF may be by a direct or indirect effect on the cerebral vascular bed by cocaine or one of its metabolites. These mechanisms have yet to be explained. Madden and Powers (5) demonstrated that certain cocaine me- 
Table 4. Cocaine metabolite levels $(\mu \mathrm{g} / L)$ after single (acute) and multiple (binge) doses of cocaine*

\begin{tabular}{|c|c|c|c|}
\hline & \multirow[b]{2}{*}{ Baseline } & \multicolumn{2}{|c|}{ Time after cocaine injection (min) } \\
\hline & & 5 & 15 \\
\hline \multicolumn{4}{|l|}{ Acute } \\
\hline Cocaine & $0 \pm 0$ & $316 \pm 170 \dagger$ & $9 \pm 12$ \\
\hline Benzoylecgonine & $0 \pm 0$ & $116 \pm 136 \dagger$ & $84 \pm 52$ \\
\hline Ecgonine methyl ester & $16 \pm 22$ & $1491 \pm 349 \dagger$ & $1278 \pm 226 \dagger$ \\
\hline \multicolumn{4}{|l|}{ Binge } \\
\hline Cocaine & $0 \pm 0$ & $675 \pm 468 \dagger$ & $174 \pm 196$ \\
\hline Benzoylecgonine & $0 \pm 0$ & $553 \pm 226 \ddagger \ddagger$ & $538 \pm 314 \dagger \ddagger$ \\
\hline Ecgonine methyl ester & $40 \pm 55$ & $2765 \pm 426 \dagger \ddagger$ & $2769 \pm 616+\ddagger$ \\
\hline
\end{tabular}

*Values expressed as mean $\pm \mathrm{SD} ; n=$ seven acute, seven binge.

$\dagger p<0.05$ compared with baseline.

$\ddagger p<0.05$ acute compared with binge.

tabolites induced vasoconstriction in isolated cat cerebral arteries. In their study, however, ecgonine methyl ester, the primary metabolite found in sheep, produced vasodilation. Dohi $e t$ al. (6) found that pial vessel vasodilation observed in cats was blocked by propranolol. They therefore hypothesized that the vasodilatory effects of cocaine appeared to be mediated, at least in part, by mechanisms that depend on stimulation of $\beta$-adrenergic receptors.

The metabolism of cocaine in sheep differs from the metabolism of cocaine in human beings. First, it is very rapid; in human beings the $t_{1 / 2}$ of a single dose of i.v. cocaine in plasma is $48 \mathrm{~min}$ (24), and in our animals it was less than $10 \mathrm{~min}$. Second, unlike human beings, in whom the major metabolite is benzoylecgonine, in sheep cocaine was primarily metabolized to ecgonine methyl ester. Fischman et al. (7) and Teeters et al. (25) reported the development of acute tachyphylaxis to cocaine in human beings and cats, respectively. They hypothesized that the reduction in the vasopressor effect of cocaine after repeated doses was due to the depletion of endogenous norepinephrine stores. It is unclear why we did not observe this phenomenon in newborn sheep; however, it may reflect differences in cocaine metabolism or species variation in the ability to replenish endogenous norepinephrine stores.

In summary, cocaine causes acute cerebral vasodilation, and this effect is prolonged after multiple doses. Although the mechanism or mechanisms for this increase in CBF remain unknown, they may be related in part to a cocaine-induced elevation in cerebral norepinephrine with a subsequent increase in $\mathrm{CMRO}_{2}$. Although it is not known whether infants who are exposed to cocaine have responses similar to newborn sheep, acute cerebral vasodilation, when combined with increases in blood pressure, may partially explain the pathogenesis of cocaine-associated intracranial hemorrhages.

Acknowledgments. The authors thank Debra Flock, Ann BiserRohrbaugh, and Bryan Lee for their expert technical assistance, Lorretta Hook for excellent secretarial support, and David Darwin and Mary Hillsgrove for their collaboration in providing assays of cocaine levels.

\section{REFERENCES}

1. Bandstra ES, Burkett G 1991 Maternal-fetal and neonatal effects of in utero cocaine exposure. Semin Perinatol 15:288-301

2. Volpe JJ 1992 Effects of cocaine on the fetus. N Engl J Med 327:399-407

3. Richie JM, Green NM 1985 Local anesthetics. In: Gilman GA, Goodman LS, Rall TW, Murad F (eds) The Pharmacological Basis of Therapeutics. MacMillan, New York, pp 302-321
4. Albuquerque ML, Kurth CD, Kim SJ, Wagerle LC 1991 Cocaine mediated cerebral vasoconstriction in newborn piglets. Pediatr Res 29:56 A(abstr)

5. Madden JA, Powers RH 1990 Effect of cocaine and cocaine metabolites on cerebral arteries in vitro. Life Sci 47:1109-1114

6. Dohi S, Jones Jr MD, Hudak ML, Traystman RJ 1990 effects of cocaine on pial arterioles in cats. Stroke 21:1710-1714

7. Fischman MW, Schuster CR, Javaid J, Yoshio H, Davis J 1985 Acute tolerance development to the cardiovascular and subjective effects of cocaine. J Pharmacol Exp Ther 235:677-682

8. Heymann MA, Payne BD, Hoffman HIE, Rudolph AM 1977 Blood flow measurements with radionuclide-labeled particles. Prog Cardiovase Dis 20:55-79

9. Cone EJ, Yousefnejad D, Darwin WD, Maguire T 1991 Testing human hair for drugs of abuse Il. Identification of unique cocaine metabolites in hair of drug abusers and evaluation of decontamination procedures. J Anal Toxicol 15:250-255

10. Nishijima JK, Breslow MJ, Raff H, Traystman RJ 1989 Regional adrena! blood flow during hypoxia in anesthetized, ventilated dogs. Am J Physiol 256: $\mathrm{H} 94-\mathrm{H} 100$

11. Gleason CA, Iida H, O'Brien TP, Jones Jr MD, Traystman RJ 1993 Fetal responses to acute maternal cocaine injection in sheep. Am J Physiol 265:H9-H14

12. Sharkey J, McBean DE, Kelly PAJ 1991 Acute cocaine administration: effects on local cerebral blood now and metabolic demand in the rat. Brain Res 548:310-314

13. Van de Bor M, Walther FJ, Sims ME 1990 Increased cerebral blood flow velocity in infants of mothers who abuse cocaine. Pediatrics 85:733-736

14. Albuquerque MLC, Kurth CD, Monitto CL, Shaw L, Anday EK 1992 Cocaine metabolites affect cerebrovascular tone in newborn piglets. Pediatr Res 31:57A(abstr)

15. Schreiber MD, Torgerson LJ, Covert RF, Madden JA 1992 Cocaine and metabolite-induced vasoconstriction of isolated pressurized cerebral arteries from perinatal lambs. Pediatr Res 31:221A(abstr)

16. Arnold BW, Martin CG, Alexander BJ, Chen T, Fleming LR 1991 Autoregulation of brain blood flow during hypotension and hypertension in infant lambs. Pediatr Res 29:110-115

17. Siesjo BK 1978 Brain energy metabolism. John Wiley \& Sons, New York, pp $56-100$

18. Rosenberg AA, Jones Jr MD, Traystman RJ, Simmons MA, Molteni RA 1982 Response of cerebral blood flow to changes in $\mathrm{PCO}_{2}$ in fetal, newborn and adult sheep. Am J Physiol 242:H862-H866

19. London ED, Wilkerson G, Goldberg SR, Risner ME 1986 Effects of L-cocaine on local cerebral glucose utilization in the rat. Neurosci Lett 68:73-78

20. London ED, Casella NG, Wong DF, Phillips RL, Dannals RF, Links JM, Herning R, Grayson R, Jaffe JH, Wagner Jr HN 1990 Cocaine-induced reduction of glucose utilization in human brain. Arch Gen Psychiatry 47:567-574

21. Anday EK, Kurth CD, Delivoria-Papadopoulos J, Wagerle LC 1991 Morphine anesthesia affects the cerebrovascular response to cocaine in the newborn piglet. Pediatr Res 29:201 A(abstr)

22. Pitts DK, Udom CE, Marwah J 1987 Neuropharmacology of cocaine: role of monoaminergic systems. Monogr Neural Sci 13:34-54

23. MacKenzie ET, McCulloch J, Harper AM 1976 Influences of endogenous norepinephrine on cerebral blood flow and metabolism. Am J Physiol 231:489-493

24. Javaid JI, Fischman MW, Schuster CR, Dekirmenjian H, Davis JM 1978 Cocaine plasma concentration: relation to physiological and subjective effects in humans. Science 202:227-228

25. Teeters WR, Koppanyi T, Cowan FF 1963 Cocaine tachyphylaxis. Life Sci $7: 509-518$ 